\title{
Pain-related psychological correlates of pediatric acute post-surgical pain
}

\author{
This article was published in the following Dove Press journal: \\ Journal of Pain Research \\ 10 November 2012 \\ Number of times this article has been viewed
}

\section{Gabrielle Pagé' \\ Jennifer Stinson ${ }^{2,3}$ \\ Fiona Campbell ${ }^{2,4}$ \\ Lisa Isaac ${ }^{2,4}$ \\ Joel Katz ${ }^{1,4,5}$}

'Department of Psychology, Faculty of Health, York University, ${ }^{2}$ Department of Anesthesia and Pain Medicine, Hospital for Sick Children, ${ }^{3}$ Lawrence $S$ Bloomberg Faculty of Nursing, University of Toronto, ${ }^{4}$ Department of Anesthesia, Faculty of Medicine, University of Toronto, ${ }^{5}$ Department of Psychology, Hospital for Sick Children, Toronto, ON, Canada
Correspondence: Joel Katz Department of Psychology, BSB 232, York University, 4700 Keele Street, Toronto, ON M3J IP3, Canada Tel +I 4167362100 ext 40557 Email jkatz@yorku.ca
Background: Post-surgical pain is prevalent in children, yet is significantly understudied. The goals of this study were to examine gender differences in pain outcomes and pain-related psychological constructs postoperatively and to identify pain-related psychological correlates of acute post-surgical pain (APSP) and predictors of functional disability 2 weeks after hospital discharge.

Methods: Eighty-three children aged 8-18 (mean $13.8 \pm 2.4$ ) years who underwent major orthopedic or general surgery completed pain and pain-related psychological measures 48-72 hours and 2 weeks after surgery.

Results: Girls reported higher levels of acute postoperative anxiety and pain unpleasantness compared with boys. In addition, pain anxiety was significantly associated with APSP intensity and functional disability 2 weeks after discharge, whereas pain catastrophizing was associated with APSP unpleasantness.

Conclusion: These results highlight the important role played by pain-related psychological factors in the experience of pediatric APSP by children and adolescents.

Keywords: acute post-surgical pain, children, adolescents, pain anxiety, pain catastrophizing

\section{Introduction}

Post-surgical pain is prevalent in pediatric populations, yet is significantly understudied. ${ }^{1}$ Research has shown that between $15 \%^{2}$ and $60 \% 0^{3-7}$ of children report moderate to severe acute postoperative pain (APSP). Prospective studies of pediatric APSP have shown that preoperative anticipatory anxiety, younger age, and lower anticipatory distress before surgery predict higher APSP intensity on the day of surgery, ${ }^{8,9}$ and negative affect and pessimistic expectations about surgery predict functional disability one week after oral surgery. ${ }^{10}$ In addition, studies conducted postoperatively have found that coping strategies, depression, and self-efficacy correlate with acute pain intensity scores following surgery among adolescents. ${ }^{11-14}$

\section{Gender differences in APSP and psychological constructs}

Clinical studies of pediatric pain reveal significant gender differences in the experience and expression of pain, with acute and chronic pain being more prevalent among girls. ${ }^{15}$ Girls with chronic pain reported higher pain intensity and frequency, higher health care utilization, medication intake, and utilization of nonpharmacological interventions, as well as a higher level of school absenteeism compared with boys with chronic pain. ${ }^{16-18}$ Girls have also reported higher levels of pain-related psychological constructs, such as anxiety sensitivity and pain catastrophizing. ${ }^{19}$ 
Gender differences have been found in some studies of perioperative pain and anxiety. For example, girls reported higher levels of preoperative anxiety and expected to experience more intense postoperative pain than did boys; girls also reported higher levels of postoperative pain intensity. ${ }^{5}$ Gender also served as a moderator of the relationship between preoperative anxiety and postoperative pain, such that preoperative anxiety was associated with higher levels of postoperative pain intensity in girls but not in boys. ${ }^{5}$ In contrast, no significant gender differences were found in APSP intensity scores among children and adolescents after spinal fusion $^{20}$ or after minor or medium surgical procedures. ${ }^{21}$ The role of gender in APSP and pain-related psychological constructs is thus unclear.

\section{Perioperative anxiety}

A significant amount of work has been done on the impact of perioperative anxiety on perioperative pain and behavior change. More specifically, children report higher levels of anxiety following surgery compared with the preoperative period, and higher levels of postoperative anxiety are associated with higher levels of pain intensity in the days following surgery. ${ }^{22}$ Preoperative anxiety was also found to predict higher pain intensity over the first 2 weeks after surgery, higher consumption of codeine and acetaminophen, and sleep difficulties. ${ }^{23}$

While anxiety appears to be an important construct in pediatric APSP, the research suggests that compared with general measures of anxiety, pain-specific constructs (eg, pain anxiety, pain catastrophizing) account for a higher proportion of variance in pain outcomes. ${ }^{24}$ Pain anxiety refers to the cognitive (eg, difficulties concentrating when in pain), emotional (eg, fear of pain-related consequences or pain amplification), physiological (eg, increased heart rate), and behavioral (eg, pain avoidance) reactions associated with the experience and/or anticipation of pain. Pain catastrophizing refers to the rumination, feeling of helplessness, and magnification of the experience of pain. ${ }^{25,26}$ Clinical and community-based studies have shown that pain anxiety and pain catastrophizing are associated with pain-related disability and pain severity in children. ${ }^{27,28}$ However, the role of pain-related anxiety in the experience of pediatric APSP has not yet been examined. ${ }^{29}$

The main goals of this study were to examine gender differences in pain outcomes and pain-related psychological constructs postoperatively and identify pain-related psychological correlates of acute post-surgical pain in the first
2 days after surgery and the predictors of functional disability 2 weeks after hospital discharge in a sample of children and adolescents undergoing major surgery.

\section{Materials and methods Participants and recruitment}

Children undergoing general surgical procedures (ie, thoracotomy, thoracoabdominal surgery, a Nuss or Ravitch surgical procedure (for pectus anomalies), sternotomy, laparotomy, ostomy) or orthopedic surgery (ie, scoliosis, osteotomy, tibial/femoral plate insertion, open hip reduction, hip capsulorrhaphy) and who were aged 8-18 years were eligible to participate in this study. Exclusion criteria were having a developmental or cognitive delay, having cancer, or not being fluent in written and/or spoken English.

\section{Questionnaires}

\section{Child Pain Anxiety Symptoms Scale}

The Child Pain Anxiety Symptoms Scale (CPASS) ${ }^{30}$ is a 20-item scale for children, and is adapted from the adult PASS-20. ${ }^{31}$ For each statement, children are asked to rate the extent to which they think, act, or feel a certain way on a scale from 0 ("never think, act or feel that way") to 5 ("always think, act, or feel that way"). Total scores range from 0 to 100 , with higher scores indicating higher levels of pain anxiety. The CPASS is composed of four subscales, ie, cognitive, escape/avoidance, fear, and physiological anxiety. The CPASS showed excellent internal consistency $(\alpha=0.90)$ in a community sample of children ${ }^{30}$ as well as in the present study ( $\alpha=0.92-0.96) .{ }^{32}$ In addition, the CPASS correlated more strongly with pain catastrophizing $(r=0.63)$ and anxiety sensitivity $(r=0.60)$ than with general anxiety ( $r=0.44)$ (suggesting adequate construct validity) and was significantly associated with how often children reported pain. ${ }^{30}$

\section{Multidimensional Anxiety Scale for Children}

The Multidimensional Anxiety Scale for Children (MASC$10)^{33}$ is a short, 10 -item version of the 39-item Multidimensional Anxiety Scale for Children. The MASC-10 items, which tap physiological symptoms, social anxiety, harm avoidance, and separation/panic, are summed to form a global anxiety symptom score. Children are asked to rate the extent to which each of the 10 statements is true about them on a scale from 0 ("never true about me") to 3 ("often true about me"). Total scores range from 0 to 30 , with higher scores indicating higher levels of anxiety. The MASC-10 has 
adequate internal consistency ( $\alpha=0.60-0.85$ ), good testretest reliability $(r=0.79-0.93)$, good convergent validity (high correlation with the Revised Children's Manifest Anxiety Scale), and good discriminant validity (absence of a significant correlation with the Children's Depression Inventory). ${ }^{33}$ Internal consistency for the present sample was adequate $(\alpha=0.73-0.84)$.

\section{Childhood Anxiety Sensitivity Index}

The Childhood Anxiety Sensitivity Index (CASI) ${ }^{34}$ assesses the extent to which the respondent interprets anxiety-related symptoms (eg, increased heart rate, feeling nauseated) as indicators of potentially harmful somatic, psychological, and/or social consequences. ${ }^{35}$ The scale is composed of 18 items such as "It scares me when my heart beats fast" and "It scares me when I feel like I'm going to throw up". Items are rated on a scale ranging from 1 ("none") to 3 ("a lot"). Total scores range from 18 to 54, with higher scores indicating higher levels of anxiety sensitivity. The CASI has good internal consistency $(\alpha=0.87)$ and test-retest reliability $(r=0.76)$ as well as adequate convergent and discriminant validity. ${ }^{34}$ Internal consistency for the present study was excellent $(\alpha=0.87-0.93)$.

\section{Pain Catastrophizing Scale-Children}

The Pain Catastrophizing Scale-Children (PCS-C) ${ }^{36}$ is a 13-item self-report measure assessing the extent to which children worry, amplify, and feel helpless about their current or anticipated pain experience. ${ }^{36}$ The scale was modified for use with children based on the adult PCS. ${ }^{25}$ For each item, children are asked to rate, on a scale from 0 ("not at all") to 4 ("extremely"), "how strongly they experience this thought" when they have pain. Total scores range from 0 to 52 , with higher scores indicating higher levels of pain catastrophizing. The PCS-C comprises three subscales, ie, rumination, magnification, and helplessness. Preliminary results suggest that the PCS-C has good internal consistency $(\alpha=0.90)$, and correlates highly with pain intensity $(r=0.49)$ and disability $(r=0.50) .{ }^{36}$ Internal consistency for the present study was excellent $(\alpha=0.93)$.

\section{Center for Epidemiological Studies-Depression Scale}

The Center for Epidemiological Studies Depression Scale for Children (CES-DC) ${ }^{37}$ is a 20 -item self-report measure that assesses depressive symptoms in children and adolescents. The questionnaire measures six broad symptom areas, including depressed mood, guilt/worthlessness, helplessness/hopelessness, psychomotor retardation, loss of appetite, and sleep disturbance. For each item, participants indicate the extent to which they have felt this way in the past week, using a scale from 0 ("not at all") to 3 ("a lot"). Total scores range from 0 to 60 , with higher scores indicating more severe depressive symptomatology. The CES-DC has good internal consistency $(\alpha=0.89)$ and good convergent validity (and is significantly correlated with the Child Trait Checklist, the Coopersmith Self-Esteem Inventory, and the Children's Global Assessment Scale). ${ }^{38}$ Internal consistency for the present study was excellent $(\alpha=0.90-0.91)$.

\section{Functional Disability Inventory}

The Functional Disability Inventory (FDI) ${ }^{39}$ is a 15 -item scale that assesses the extent to which children experience difficulties in completing specific tasks (eg, "Walking to the bathroom", "Eating regular meals", and "Being at school all day"). Typically, the FDI is used as a five-point Likert scale and yields total scores ranging from 0 to 60 . Inadvertently, the FDI in the present study was measured using a four-point Likert scale and omitted the original " 2 " ("some trouble"). Children in this study rated each item on a scale from 0 to 3, ie, (0, "no trouble"; 1, "a little trouble"; 2, "a lot of trouble"; and 3, "impossible"), yielding total scores ranging from 0 to 45 . The FDI has excellent internal consistency $(\alpha=0.86-0.91)$ and good test-retest reliability at 2 weeks $(r=0.74)$ and 3 months $(r=0.48) .{ }^{39}$ The FDI has been used with many pediatric populations, including children with chronic pain ${ }^{40-42}$ and post-surgical pain. ${ }^{10}$ Internal consistency for the present study was excellent $(\alpha=0.83-0.89)$.

\section{Numerical Rating Scale for pain intensity and pain unpleasantness}

The Numerical Rating Scale (NRS) is a verbally administered scale that measures pain intensity ("How much pain do you feel right now?"). The NRS was also used to measure pain unpleasantness ("How unpleasant/horrible/yucky is the pain right now?"). The end points represent the extremes of the pain experience. Because there are no agreed upon NRS anchors for measuring pain in children and adolescents,${ }^{43}$ the following anchors were used in the present study: for pain intensity, $0=$ "no pain at all" to $10=$ "worst possible pain"; for pain unpleasantness, $0=$ "not at all unpleasant/horrible/yucky" to $10=$ "most unpleasant/horrible/yucky feeling possible". 
The NRS for pain intensity has been validated as an APSP measure in children aged seven to 17 years, and correlated highly with the Visual Analog Scale $(r=0.89)$ and the Faces Pain Scale-Revised $(r=0.87) .{ }^{44}$

\section{Preoperative pain experience}

The children were asked retrospectively (48-72 hours after surgery), to answer the following question: "Before surgery, how much pain did you have in general?" using one of four verbal descriptors: no pain; a little bit of pain; a medium amount of pain; or a lot of pain.

\section{Hospital chart review}

The following information was collected from the children's hospital charts: preoperative information (eg, ongoing pain problems, regular pain medications, previous surgery), perioperative information (eg, type of procedure, length of surgery) and postoperative information (eg, pain medication on the first day after surgery).

\section{Procedure}

The study was reviewed and approved by the research ethics boards of the Hospital for Sick Children and York University. Nurses not involved in the research project approached potential participants 48-72 hours after surgery to assess their interest in learning about this research. Interested children and one of their parents were then approached by a research team member. Written parental consent and consent or assent from the children were then obtained. A member of the research team then read to the child the CPASS, PCS-C, CASI, MASC-10, CES-DC, FDI, NRS-Pain Intensity (NRS-I), NRS-Pain Unpleasantness (NRS-U), and the Preoperative Pain Experience questionnaire and recorded their responses to each item. Potential order and fatigue effects were minimized by randomizing the order of administration of questionnaires within participants (http:// www.randomization.com). Telephone follow-ups were done approximately 2 weeks after discharge from hospital by a research assistant who verbally administered the CPASS, FDI, NRS-I, and NRS-U to the children. Parents also completed measures, and these results will be presented in a separate paper.

\section{Data analysis}

\section{Data screening}

Testing of skewness and the significance of kurtosis (estimate/standard error $>3$ ) revealed non-normality of pain intensity (NRS-I) and pain unpleasantness (NRS-U)
2 weeks after discharge from hospital. Non-normality of the distribution of these two variables was addressed by squareroot transformation [NRS-I $(2)^{t}$, NRS-U(2) $\left.{ }^{t}\right]$.

\section{Descriptive statistics}

Univariate analysis of variance was used to examine differences in pain intensity (model 1) and pain unpleasantness (model 2) scores 48-72 hours after surgery and 2 weeks after discharge (NRS-I, model 3; NRS-U, model 4) across the different types of surgical procedure. In addition, the Pearson Chi-square test was used to examine gender differences across types of surgical procedures.

Two-tailed $t$-tests with Bonferroni correction $(\alpha=0.017)$ were used to examine differences in NRS-I and NRS-U scores 48-72 hours after surgery and analgesic consumption (in morphine equivalents) on the first day following surgery in children who had prior surgical experience versus those who did not. In addition, a series of three two-tailed $t$-tests with Bonferroni correction $(\alpha=0.017)$ was used to examine differences in NRS-I $(2)^{t}, \mathrm{NRS}-\mathrm{U}(2)^{\mathrm{t}}$, and functional disability scores $[\mathrm{FDI}(2)]$ in children who had prior surgical experience versus those who did not.

A multivariate analysis of variance was used to examine whether or not prior surgical experience was associated with children's self-report on the CPASS, PSC-C, CASI, MASC-10, and CES-DC at 48-72 hours after surgery. A significant omnibus effect on the multivariate analysis of variance was followed by an examination of the univariate tests.

\section{Gender differences in postoperative pain-related psychological constructs}

Two-tailed $t$-tests were used to look for any gender differences in psychological measures and pain outcomes 48-72 hours and 2 weeks after surgery.

\section{Correlates of APSP and predictors of functional disability}

Linear regression analyses examined whether pain-related psychological factors were associated with pain intensity [NRS-I(0)] and pain unpleasantness [NRS-U(0)] 48-72 hours after surgery. In each model, age, gender, and analgesic consumption $\left(\mathrm{mg} / \mathrm{kg}\right.$ in morphine equivalents ${ }^{45}$ ) were entered in the first step, followed by CES-DC(0) and MASC-10(0) in order to control for depression and anxiety. In the third step, $\operatorname{CPASS}(0), \operatorname{PCSC}(0)$, and $\operatorname{CASI}(0)$ were entered stepwise in the model. Alpha levels for the overall models were adjusted $(\alpha=0.025)$ using Bonferroni correction. 
Linear regression analyses examined whether pain-related psychological factors predicted pain intensity [NRS-I(2) $\left.{ }^{t}\right]$, pain unpleasantness [NRS-U(2) $]$, and functional disability (FDI[2]) 2 weeks after discharge from hospital. In each model, age, gender, and analgesic consumption $(\mathrm{mg} / \mathrm{kg}$ in morphine equivalents) were entered first, followed by CES-DC $(0)$ and $\operatorname{MASC}(0)$ in order to control for depression and anxiety. In the third step, $\operatorname{CPASS}(0), \operatorname{PCSC}(0)$, and $\operatorname{CASI}(0)$ were entered stepwise into the model. Alpha levels for the overall models were adjusted ( $\alpha=0.017)$ using Bonferroni correction.

All statistical analyses were conducted using the Statistical Package for the Social Sciences version 19 (SPSS Inc, Chicago, IL).

\section{Sample size estimation}

The sample size was estimated a priori using G*Power version 3.1. ${ }^{46} \mathrm{~A}$ sample size of 50 participants would be required for a Pearson Chi-square test to detect a medium to large effect size $(\mathrm{w}=0.40)$ with $\alpha=0.05$, power $=80 \%$, and $\mathrm{df}=1$. Seventy-eight participants would be required to ensure $\alpha=0.05$ and power $=80 \%$, with a medium to large effect size two-tailed independent samples $t$-test. Sample size analysis showed that 58 participants would be required for a one-way multivariate analysis of variance, with five response variables and two groups in the independent variable to ensure $\alpha=0.05$ and power $=80 \%$. A linear regression analysis with $\alpha=0.025$ and power $=80 \%$, using seven predictors and a medium to large effect size ( $f^{2}=0.25$ ), would require a sample size of 76 participants. Thus, allowing for attrition, we attempted to recruit a total sample size of 80 participants.

\section{Results}

\section{Recruitment}

Recruitment took place between July 2008 and September 2010. Eighty-three children/parents (56 [67.5\%] females) aged 8-18 (mean $13.8 \pm 2.4$ ) years (girls $14.0 \pm 2.3$ years; boys $13.5 \pm 2.6$ years) participated in the study, and 69 $(83 \%)$ completed the telephone follow-up approximately 2 weeks after discharge from hospital (mean 15.6 \pm 2.15 days). Fourteen participants could not be reached or were away on vacation during the time of follow-up. Details of the recruitment process are shown in Table 1.

\section{Descriptive statistics}

The majority of children in this sample self-identified as Caucasian $(\mathrm{n}=53,64 \%)$ and as speaking English as their first language at home $(n=74,89 \%)$. Forty-two children underwent spinal fusion for scoliosis (50.6\%),
Table I Recruitment process

\begin{tabular}{ll}
\hline Total number of eligible participants & 534 \\
Reason not recruited & \\
No research staff available & 95 \\
Developmental/cognitive delays & 78 \\
Discharged & 71 \\
Parent absent & 40 \\
Noncommunicative & 31 \\
Sleeping & 22 \\
Pediatric intensive care unit & 21 \\
Parents not fluent in English & 19 \\
Undergoing other medical procedures & 6 \\
Other & 3 \\
Total number of potential participants approached & 148 \\
Reason for refusal to participate & \\
Not interested & 18 \\
Too tired & 16 \\
Too nauseous & 12 \\
Parents too busy & 5 \\
Already in other studies & 4 \\
Too much pain & 3 \\
Too sleepy & 3 \\
Other & 4 \\
Total number of participants & 83 \\
Lost to follow-up & 14 \\
Total number of completed follow-up 2 weeks after discharge & 69 \\
\hline &
\end{tabular}

25 underwent osteotomy (30.1\%), eight (9.6\%) underwent a Nuss $(\mathrm{n}=5)$ or Ravitch $(\mathrm{n}=3)$ procedure, seven underwent $(8.4 \%)$ laparotomy, and one child had a thoracotomy. Approximately half of the children $(\mathrm{n}=39,47 \%)$ had previously undergone a surgical procedure in the past (mean number of surgeries $=2.0 \pm 1.6$, range $1-7$ ), while this was a novel experience for 44 children (53\%). The majority of children $(80.7 \%)$ reported retrospectively that they had "no pain" or "a little bit of pain" before the surgery.

The mean duration of surgery was $317.5 \pm 141.3$ minutes and the mean time spent in the post anesthesia care unit was $181.2 \pm 143.3$ minutes. Details of analgesics used intraoperatively, in the post anesthesia care unit, and on the first day after surgery are shown in Table 2 . The mean morphineequivalent analgesic consumption on the day following surgery was $1.21 \pm 1.02 \mathrm{mg} / \mathrm{kg}(62.81 \pm 57.6 \mathrm{mg})$.

Significant differences were not found in pain intensity or pain unpleasantness scores 48-72 hours after surgery and 2 weeks after discharge from hospital across the different types of surgical procedures. Chi-square testing revealed significant gender differences across the types of surgical procedures $\left(\chi^{2}=23.25, P<0.001\right)$, in that fewer boys had surgery for scoliosis than expected by chance and more boys had a Nuss or Ravitch procedure than expected by chance. 
Table 2 Peri-operative Information

\begin{tabular}{|c|c|}
\hline SURGERY & Mean (SD) \\
\hline Surgery Time (minutes) & $317.5(141.3)$ \\
\hline Intraoperative Opioids & n (\%) \\
\hline Fentanyl + Remifentanil + Morphine & $20(24.0)$ \\
\hline Fentanyl + Morphine & $23(27.7)$ \\
\hline Remifentanil + Morphine & $12(14.5)$ \\
\hline Fentanyl & II (I3.2) \\
\hline Fentanyl + Other & $7(8.4)$ \\
\hline Fentanyl + Remifentanil & $3(3.6)$ \\
\hline Morphine & $2(2.5)$ \\
\hline Other & $2(2.5)$ \\
\hline Remifentanil & $\mathrm{I}(\mathrm{I} .2)$ \\
\hline Intraoperative opioid data not available & $2(2.5)$ \\
\hline PACU & Mean (SD) \\
\hline Time in PACU & $181.2(143.3)$ \\
\hline PACU analgesics & n (\%) \\
\hline Morphine & $28(33.8)$ \\
\hline Acetaminophen + Morphine & $26(31.4)$ \\
\hline Acetaminophen + Fentanyl & $5(6.0)$ \\
\hline Acetaminophen + Other & $5(6.0)$ \\
\hline Acetaminophen + Hydromorphone & $5(6.0)$ \\
\hline Other & $4(4.8)$ \\
\hline Hydromorphone & $2(2.4)$ \\
\hline Fentanyl & $2(2.4)$ \\
\hline Acetaminophen + NSAID + Morphine & $\mathrm{I}(\mathrm{I} .2)$ \\
\hline Acetaminophen + NSAID & $\mathrm{I}(\mathrm{I} .2)$ \\
\hline Acetaminophen & $\mathrm{I}(\mathrm{l} .2)$ \\
\hline PACU analgesic data not available & $3(3.6)$ \\
\hline \multicolumn{2}{|l|}{ DAY I } \\
\hline Acetaminophen and NSAIDs & n (\%) \\
\hline Acetaminophen PO & $50(60.2)$ \\
\hline Acetaminophen PR & $13(15.7)$ \\
\hline Acetaminophen PO +NSAID IV & $9(10.8)$ \\
\hline Acetaminophen PO +NSAID PO & $2(2.5)$ \\
\hline Acetaminophen PR+NSAID IV & $\mathrm{I}(\mathrm{I} .2)$ \\
\hline Acetaminophen PR+NSAID PO & $\mathrm{I}(\mathrm{I} .2)$ \\
\hline NSAID PO & $\mathrm{I}(\mathrm{I} .2)$ \\
\hline Day I analgesic consumption not available & $6(7.2)$ \\
\hline Opioids & n (\%) \\
\hline Morphine IV & $50(60.2)$ \\
\hline Hydromorphone IV & $12(14.5)$ \\
\hline Fentanyl IV & $6(7.2)$ \\
\hline Morphine IV + Hydromorphone IV & $\mathrm{I}(\mathrm{I} .2)$ \\
\hline Morphine IV + Other & $\mathrm{I}(\mathrm{I} .2)$ \\
\hline Morphine PO + Fentanyl IV & $\mathrm{I}(\mathrm{I} .2)$ \\
\hline Other & $3(3.6)$ \\
\hline \multirow[t]{2}{*}{ Day I analgesic consumption not available } & $9(10.9)$ \\
\hline & Mean (SD) \\
\hline Least Pain Score (NRS) & $1.50(1.6)$ \\
\hline Highest Pain Score (NRS) & $4.8 \mathrm{I}(2.5)$ \\
\hline
\end{tabular}

Abbreviation: NRS, Numerical Rating Scale; NSAID, nonsteroidal anti-inflammatory drug; PACU, post anesthesia care unit; PO, orally; PR, per rectum; IV, intravenously; $\mathrm{SD}$, standard deviation.

\section{Differences associated with prior surgery}

Significant differences were not found in pain intensity $(P=0.574)$ or pain unpleasantness $(P=0.995)$ 48-72 hours after surgery or in morphine-equivalent analgesic consumption $(\mathrm{mg} / \mathrm{kg})$ on the day after surgery $(P=0.584)$ in children who had prior surgical experience versus those who did not. In addition, significant differences were not found between children who had prior surgical experience versus those who did not on measures of pain intensity ( $P=0.433)$, pain unpleasantness $(P=0.689)$, or functional disability levels $(P=0.632) 2$ weeks after discharge from hospital.

Results of the multivariate analysis of variance at 48-72 hours after surgery showed an overall significant effect [Pillai's trace $=0.198, \mathrm{~F}(5,74)=3.66, P=0.005$ ] Examination of the univariate tests indicated that children who had never previously undergone surgery scored significantly higher on anxiety sensitivity [mean CASI score $35.07 \pm 6.5,(\mathrm{~F}(1,78)=6.24, P=0.015]$ and general anxiety [mean MASC-10 score $13.20 \pm 4.6, \mathrm{~F}(1,78)=7.40$, $P=0.008]$ than children who had undergone surgery in the past (mean CASI score $31.14 \pm 7.6$; mean MASC-10 score $10.05 \pm 5.8)$.

\section{Gender differences in postoperative pain-related psychological constructs}

Mean values for boys and girls on the relevant psychological and pain measures are shown in Table 3. Significant gender differences were observed on anxiety sensitivity [mean difference of 4.32 in CASI score, $t(1,81)=2.59, P=0.011$ ], general anxiety [mean difference of 3.30 in MASC-10 score, $t(1,79)=2.73, P=0.008$ ] , and pain unpleasantness [mean difference of 1.28 in NRS-U score, $t(1,81)=2.01, P=0.048]$ 48-72 hours after surgery, such that girls scored higher compared with boys on these measures. Girls also scored significantly higher on functional disability [mean difference of $4.83, t(1,67)=2.20, P=0.031] 2$ weeks after discharge compared with boys, but this difference was no longer significant when taking into account only children who reported experiencing pain 2 weeks after discharge from hospital $(P=0.090)$. There were no gender differences in morphine-equivalent analgesic consumption on the first day after surgery $(P=0.194)$.

\section{Correlates of APSP and predictors of functional disability}

Results of the linear regression analyses 48-72 hours after surgery showed that age $(\beta=0.26, P=0.030)$, depression (CES-DC, $\beta=0.36, P=0.025$ ), anxiety (MASC-10, $\beta=-0.38, P=0.027$ ) and pain anxiety (CPASS, $\beta=0.51$, $P=0.001)$ were significantly associated with pain intensity [NRS-I, F $6 ; 49)=5.97$, adjusted $\mathrm{R}^{2}=0.35, \mathrm{R}^{2}$ change $=0.15$, $P<0.001]$ and that morphine-equivalent $(\mathrm{mg} / \mathrm{kg})$ analgesic 
Table 3 Mean (standard deviation) of pain and related psychological variables for boys, girls, and the total sample when measured 48-72 hours after surgery and 2 weeks after discharge

\begin{tabular}{|c|c|c|c|c|c|c|}
\hline & \multicolumn{3}{|c|}{ 48-72 hours after surgery $(0)$} & \multicolumn{3}{|c|}{ Two weeks after discharge (2) } \\
\hline & Boys & Girls & Total & Boys & Girls & Total \\
\hline Pain anxiety (CPASS) & $46.11(18.9)$ & $48.09(19.5)$ & $47.45(19.2)$ & $35.23(16.4)$ & $38.77(19.4)$ & $37.64(18.4)$ \\
\hline Pain catastrophizing (PCSC) & $21.69(12.7)$ & $21.91(12.1)$ & $21.84(12.2)$ & & & \\
\hline Anxiety sensitivity (CASI) & $30.00(6.0)^{\dagger}$ & $34.32(7.6)$ & $32.92(7.4)$ & & & \\
\hline Depression (CES-DC) & $22.70(10.4)$ & $23.55(12.4)$ & $23.27(11.7)$ & & & \\
\hline Anxiety (MASC-I0) & $9.54(4.9)^{\dagger}$ & $12.84(5.2)$ & $1 \mathrm{I} .74(5.3)$ & & & \\
\hline \multirow[t]{2}{*}{ Pain } & Yes $=23$ & Yes $=53$ & Yes $=76$ & Yes $=14$ & Yes $=38$ & Yes $=52$ \\
\hline & $\mathrm{No}=4$ & $\mathrm{No}=3$ & No $=7$ & No $=8$ & No $=9$ & $\mathrm{No}=17$ \\
\hline Pain intensity (NRSI)* & $3.44(2.4)$ & $4.06(2.3)$ & $3.86(2.3)$ & $2.20(2.1)$ & $2.32(2.2)$ & $2.28(2.2)$ \\
\hline Pain unpleasantness (NRSU)* & $3.70(2.6)^{\dagger}$ & $4.98(2.8)$ & $4.57(2.8)$ & $2.23(2.3)$ & $2.73(2.7)$ & $2.57(2.6)$ \\
\hline Functional disability (FDI)* & & & & $16.32(9.4)^{\dagger}$ & $21.15(8.0)$ & 19.6I (8.8) \\
\hline
\end{tabular}

Notes: *Pain intensity, pain unpleasantness, and functional disability scores are computed only for children who reported experiencing pain and do not take into account children who did not endorse pain at each time point. 'Signficant difference between boys and girls $(P<0.05)$.

Abbreviations: CPASS, Child Pain Anxiety Symptoms Scale; PCSC, Pain Catastrophizing Scale-Children; CASI, Childhood Anxiety Sensitivity Index; CES-DC, Center for Epidemiological Studies-Depression Scale for Children; MASC-10, Multidimensional Anxiety Scale for Children-I0; NRSI, Numerical Rating Scale for Pain Intensity; NRSU, Numerical Rating Scale for Pain Unpleasantness; FDI, Functional Disability Inventory.

consumption $(\beta=-0.27, P=0.042)$ and pain catastrophizing (PCS-C, $\beta=0.32, P=0.042$ ) were significantly associated with pain unpleasantness $[\mathrm{NRS}-\mathrm{U}, \mathrm{F}(6 ; 52)=3.05$, adjusted $\mathrm{R}^{2}=0.18, \mathrm{R}^{2}$ change $\left.=0.06, P=0.012\right]$. Details of the regression analyses are presented in Table 4.

Results of the linear regression analyses 2 weeks after discharge from hospital failed to show any significant predictors (measured 48-72 hours after surgery) of pain intensity [NRS-I $\left.{ }^{\mathrm{t}}, \mathrm{F}(5 ; 43)=1.95, P=0.11\right]$ or pain unpleasantness $\left[\mathrm{NRS}-\mathrm{U}^{\mathrm{t}}, \mathrm{F}(5 ; 43)=1.76, P=0.15\right]$. However, pain anxiety (CPASS, $\beta=0.33, P=0.013$ ) measured 48-72 hours after surgery significantly predicted levels of functional disability 2 weeks after discharge from hospital $[\mathrm{F}(6 ; 42)=5.32$, adjusted $\mathrm{R}^{2}=0.35, \mathrm{R}^{2}$ change $\left.=0.09, P<0.001\right]$. Details of the regression analyses are shown in Table 5. A graphic summary of the results is presented in Figure 1.

\section{Discussion}

The study objectives were to examine gender differences in pain outcomes and pain-related psychological constructs postoperatively and to identify pain-related psychological correlates of APSP and functional disability in a sample of children and adolescents undergoing major surgery.

\section{Gender differences in pain-related psychological constructs postoperatively and APSP}

Significant gender differences were found in pain unpleasantness, but not in pain intensity scores, at 48-72 hours after surgery. This suggests that girls are more vulnerable to the affective, but not to the sensory aspect, of APSP compared with boys. This gender difference had dissipated 2 weeks after discharge from hospital, suggesting that after time has elapsed from the painful event, girls and boys tended to react affectively in an increasingly similar fashion. The gender differences observed in the affective component of the pain experience were not reflected in the pain-related psychological constructs, such as pain anxiety and pain catastrophizing. While girls are not more anxious and do not catastrophize more about their APSP experience than boys, they do report more unpleasantness from their pain experience.

The absence of gender differences in APSP intensity is not consistent with the adult literature. Female gender has been identified as a risk factor for the development of APSP. ${ }^{47}$ The presence of gender differences in children and adolescents is more ambiguous in the pediatric literature. As discussed previously, clinical studies have shown that girls are more likely to report acute and chronic pain. ${ }^{15}$ However, results from this study are consistent with experimental studies showing that pain responses of boys and girls are comparable. ${ }^{48-50}$

Overall, girls reported higher levels of functional disability compared with boys, but significant gender differences were not found in levels of functional disability when only children were included who reported APSP 2 weeks after discharge from hospital. These results suggest that girls with APSP are no more likely than boys with APSP to report high levels of functional disability. This is in contrast with other studies of children and adolescents with chronic pain which found that girls report higher levels of functional disability compared with boys. ${ }^{39,51}$ It is possible that gender differences in functional disability emerge over time after children's pain has become chronic. 
Table 4 Pain-related psychological variables (48-72 hours after surgery) associated with APSP (48-72 hours after surgery) intensity and unpleasantness using linear regression analysis

\begin{tabular}{|c|c|c|c|c|c|c|c|}
\hline & $\beta$ & $\mathbf{t}$ & $P$ & $\mathbf{F}$ & df & Adj $R^{2}$ & $\mathbf{R}^{2}$ change \\
\hline \multicolumn{8}{|l|}{ Pain intensity } \\
\hline Step I & & & 0.270 & 1.35 & $3 ; 52$ & 0.02 & 0.07 \\
\hline Age & 0.25 & 1.85 & 0.069 & & & & \\
\hline Gender & -0.03 & -0.24 & 0.809 & & & & \\
\hline Morphine equivalent & -0.11 & -0.82 & 0.413 & & & & \\
\hline Step 2 & & & 0.006 & 3.73 & $5 ; 50$ & 0.20 & 0.20 \\
\hline Age & 0.34 & 2.71 & 0.009 & & & & \\
\hline Gender & -0.06 & -0.45 & 0.654 & & & & \\
\hline Morphine equivalent & -0.10 & -0.82 & 0.419 & & & & \\
\hline CES-DC & 0.56 & 3.42 & 0.001 & & & & \\
\hline MASC-I0 & -0.19 & $-I . I I$ & 0.273 & & & & \\
\hline Step 3 & & & 0.001 & 5.97 & $6 ; 49$ & 0.35 & 0.15 \\
\hline Age & 0.26 & 2.24 & 0.030 & & & & \\
\hline Gender & -0.09 & -0.72 & 0.473 & & & & \\
\hline Morphine equivalent & -0.11 & -0.95 & 0.349 & & & & \\
\hline CES-DC & 0.36 & 2.31 & 0.025 & & & & \\
\hline MASC-I0 & -0.38 & -2.28 & 0.027 & & & & \\
\hline CPASS & 0.51 & 3.58 & 0.001 & & & & \\
\hline \multicolumn{8}{|l|}{ Pain unpleasantness } \\
\hline Step I & & & 0.109 & 2.11 & $3 ; 55$ & 0.05 & 0.10 \\
\hline Age & 0.10 & 0.75 & 0.457 & & & & \\
\hline Gender & -0.22 & -1.72 & 0.092 & & & & \\
\hline Morphine equivalent & -0.26 & -1.96 & 0.056 & & & & \\
\hline Step 2 & & & 0.034 & 2.62 & $5 ; 53$ & 0.12 & 0.10 \\
\hline Age & 0.16 & 1.26 & 0.275 & & & & \\
\hline Gender & -0.24 & -1.78 & 0.081 & & & & \\
\hline Morphine equivalent & -0.25 & -1.86 & 0.068 & & & & \\
\hline CES-DC & 0.38 & 2.29 & 0.026 & & & & \\
\hline MASC-10 & -0.12 & -0.67 & 0.508 & & & & \\
\hline Step 3 & & & 0.012 & 3.05 & $6 ; 52$ & 0.18 & 0.06 \\
\hline Age & 0.16 & 1.22 & 0.226 & & & & \\
\hline Gender & -0.25 & -1.97 & 0.054 & & & & \\
\hline Morphine equivalent & -0.27 & -2.08 & 0.042 & & & & \\
\hline CES-DC & 0.26 & 1.55 & 0.127 & & & & \\
\hline MASC-I0 & -0.22 & -1.25 & 0.216 & & & & \\
\hline PCSC & 0.32 & 2.09 & 0.042 & & & & \\
\hline
\end{tabular}

Abbreviations: Adj, adjusted; APSP, acute post-surgical pain; CPASS, Child Pain Anxiety Symptoms Scale; PCSC, Pain Catastrophizing Scale-Children; CESD-C, Center for Epidemiological Studies-Depression Scale for Children; MASC-10, Multidimensional Anxiety Scale for Children-10.

Significant gender differences in analgesic consumption were not found on the first day after surgery. These results are consistent with some findings in the adult literature. One review of the literature suggests that approximately $45 \%$ of studies failed to show a significant gender difference in opioid use, while $55 \%$ of studies found that males are more likely to consume a greater amount of opioid medication postoperatively. ${ }^{52}$ The results are also consistent with a study of APSP which failed to show gender differences in the use of opioid analgesics among adolescents undergoing surgery. ${ }^{5}$

Analgesic consumption on the day after surgery was significantly associated with pain unpleasantness, but not pain intensity 48-72 hours after surgery, such that children with a higher intake of analgesic reported less pain unpleasantness. These results suggest that analgesic consumption in these children is associated with the affective dimension of the pain experience more than the sensory dimension. In contrast, a study of children undergoing adenoidectomy found that analgesic consumption in the post anesthesia care unit was significantly associated with intensity of APSP. ${ }^{53}$

\section{Correlates of APSP and predictors of functional disability}

Pain anxiety and pain catastrophizing were associated with pain intensity and unpleasantness, respectively, 48-72 hours after surgery. In contrast, pain anxiety measured 48-72 hours 
Table 5 Pain-related psychological variables (48-72 hours after surgery) associated with APSP ( 2 weeks after discharge) intensity and unpleasantness and functional disability using linear regression analysis

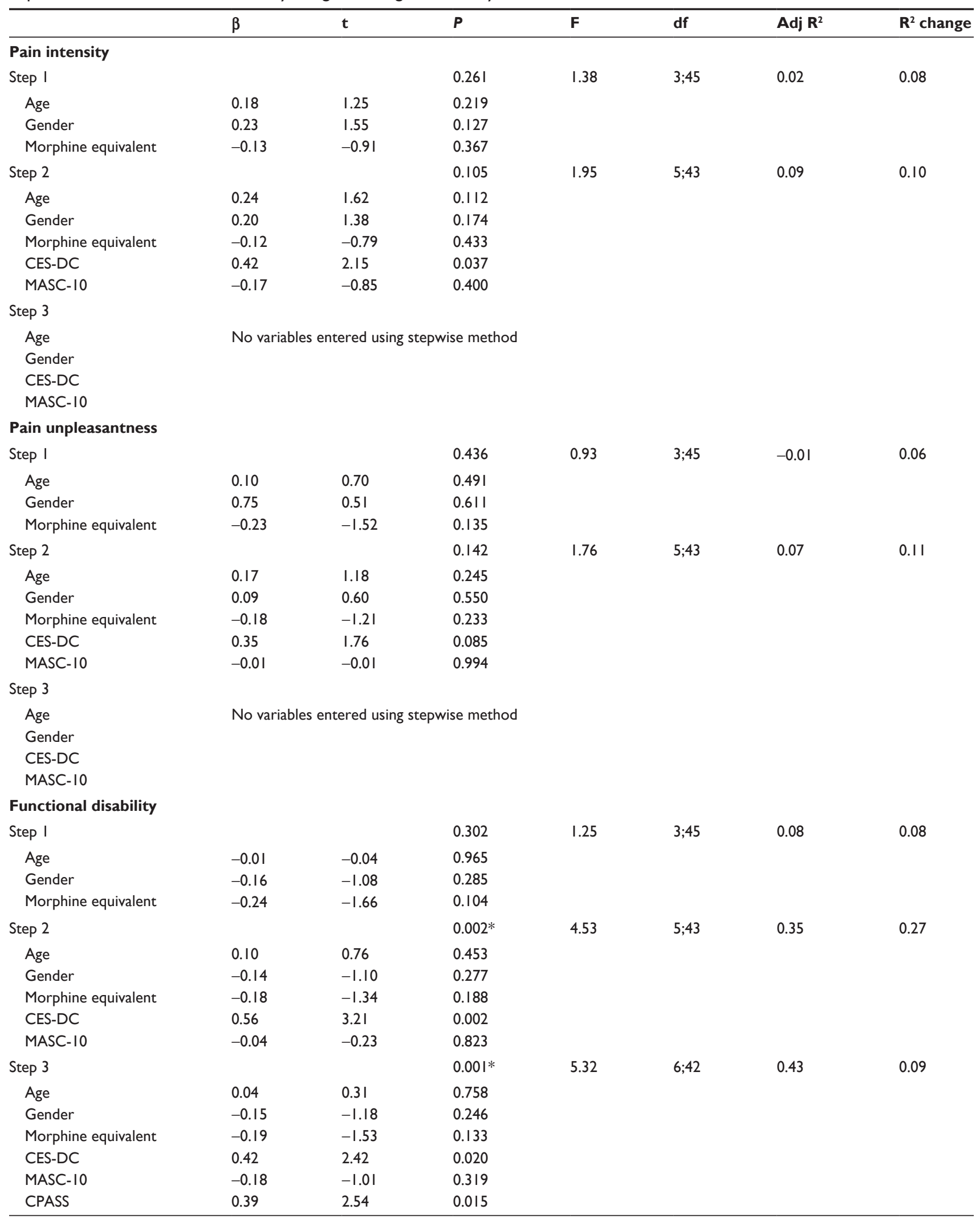

Note: $P<0.05$

Abbreviations: Adj, adjusted; APSP, acute post-surgical pain; CPASS, Child Pain Anxiety Symptoms Scale; PCSC, Pain Catastrophizing Scale-Children; CESD-C, Center for Epidemiological Studies-Depression Scale for Children; MASC-10, Multidimensional Anxiety Scale for Children-I0. 


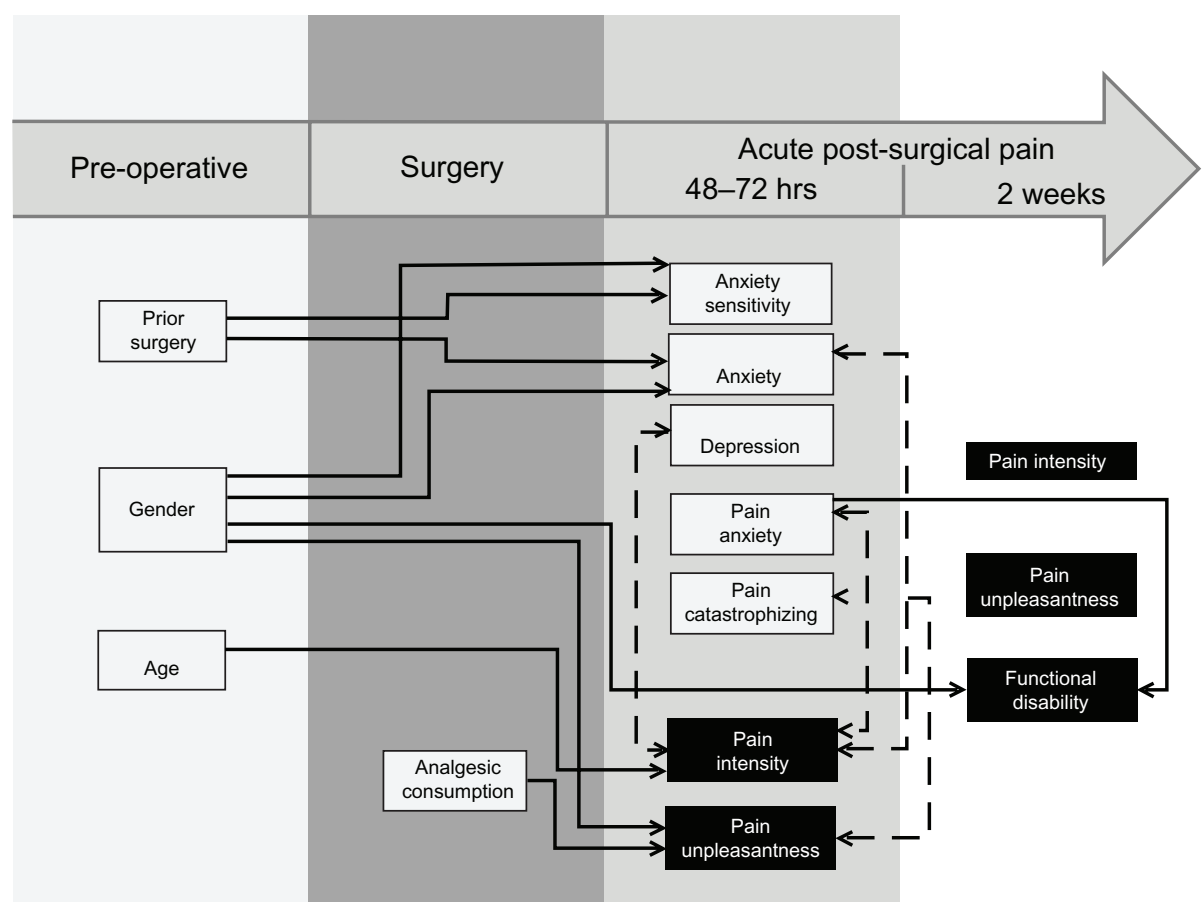

Figure I Summary of results showing that children who were surgery-naïve had higher levels of anxiety sensitivity and general anxiety compared with children who had undergone surgery in the past.

Notes: Girls reported higher levels of anxiety sensitivity, general anxiety, and pain unpleasantness $48-72$ hours after surgery, as well as functional disability 2 weeks after discharge compared with boys. Age, depression, general anxiety, and pain anxiety scores were significantly associated with pain intensity, while analgesic consumption and pain catastrophizing were significantly associated with pain unpleasantness 48-72 hours after surgery. Levels of pain anxiety 48-72 hours after surgery predicted levels of functional disability 2 weeks after discharge from hospital. Plain one-sided arrows represent predictors of pain outcomes. Long-dashed, double-sided arrows represent correlates of pain outcomes. Short-dashed arrows represent predictors of changes in pain and functional disability over time. Black boxes represent pain and functional disability outcomes. Gray boxes represent predictors and correlates.

after surgery, but not pain catastrophizing, significantly predicted levels of functional disability 2 weeks after discharge from hospital. These results suggest that $48-72$ hours after surgery, when pain is at its most intense, children are most anxious about the pain experience while they tend to amplify, ruminate, and feel powerless in the presence of the unpleasant quality of the pain experience. By the 2-week follow-up, after the children have returned home, their ability to perform their everyday activities appears to be limited by pain-related anxiety.

Consistent with a study of children who underwent spinal fusion, ${ }^{20}$ the present findings show that prior surgical experience was not associated with higher APSP intensity. APSP is typically associated with central sensitization and other changes in nociceptive processing in the central nervous system. ${ }^{54}$ These results suggest that individuals who have previously undergone surgery without developing CPSP are not more susceptible to subsequent pain experiences or to developing CPSP due to a subsequent surgery.

Prior surgical experience was associated with lower levels of anxiety and anxiety sensitivity 48-72 hours after surgery, raising the possibility that it is protective against psychological distress experienced in the acute post-surgical period. Children who have previously undergone surgery might have clearer expectations of the perioperative and recovery processes, resulting in lower anxiety relative to surgery-naïve children. However, it may also reflect a sampling bias, in that among patients who have had previous surgery, only those with low anxiety and anxiety sensitivity agreed to participate.

\section{Limitations}

There are some limitations to this study. First, no preoperative measures were collected, which would have allowed the examination of baseline levels of pain-related psychological constructs before the acute pain event. Second, results from this study cannot be generalized to minor surgical procedures because all participants in this sample underwent major surgery. Third, given that the response rate for this study was $55 \%$, children with higher APSP or higher levels of postoperative anxiety or pain catastrophizing refused to participate. Fourth, the FDI in the present study was measured using a 
four-point Likert scale and omitted the original " 2 " ("some trouble"), making it difficult to compare levels of functional disability in this study with other studies of pediatric postsurgical pain.

In conclusion, the present results show that compared with boys, girls exhibit higher levels of acute postoperative anxiety and pain unpleasantness 48-72 hours, after surgery as well as higher levels of functional disability 2 weeks after discharge from hospital. Girls and boys reported similar levels of APSP intensity. In addition, pain anxiety is significantly associated with APSP intensity and functional disability, while pain catastrophizing is associated with APSP unpleasantness. These results highlight the importance of the role pain-related psychological factors can play in the experience of APSP in children and adolescents. Future research directions include examination of biological and psychological mechanisms underlying the relationship between pain-related constructs and APSP, as well as the development of interventions to decrease the pain experience for children with elevated levels of pain anxiety and pain catastrophizing shortly after major surgery.

\section{Acknowledgments}

MGP is supported by a Canada Graduate Scholarship Doctoral Award from the Canadian Institutes of Health Research. MGP is the recipient of a Lillian Wright Maternal Child Health Scholarship from York University, and a trainee member of Pain in Child Health and a Canadian Institutes of Health Research Strategic Training Fellow in Pain: Molecules to Community. JS is supported by a Ministry of Health and Long-term Care Career Scientist Award. JK is supported by a Canadian Institutes of Health Research Canada Research Chair in Health Psychology at York University

\section{Disclosure}

The authors report no conflicts of interest in this work.

\section{References}

1. McGrath PA, Ruskin DA. Caring for children with chronic pain: ethical considerations. Paediatr Anaesth. 2007;17(6):505-508.

2. Karling M, Renstrom M, Ljungman G. Acute and postoperative pain in children: a Swedish nationwide survey. Acta Paediatr. 2002;91(6):660-666.

3. Alex MR, Ritchie JA. School-aged children's interpretation of their experience with acute surgical pain. J Pediatr Nurs. 1992;7(3):171-180.

4. Mather L, Mackie J. The incidence of postoperative pain in children. Pain. 1983;15(3):271-282.

5. Logan DE, Rose JB. Gender differences in post-operative pain and patient controlled analgesia use among adolescent surgical patients. Pain. 2004;109(3):481-487.
6. Polkki T, Pietila AM, Vehvilainen-Julkunen K. Hospitalized children's descriptions of their experiences with postsurgical pain relieving methods. Int J Nurs Stud. 2003;40(1):33-44.

7. Romsing J, Walther-Larsen S. Postoperative pain in children: a survey of parents' expectations and perceptions of their children's experiences. Paediatr Anaesth. 1996;6(3):215-218.

8. Palermo TM, Drotar D. Prediction of children's postoperative pain: The role of presurgical expectations and anticipatory emotions. $J$ Pediatr Psychol. 1996;21(5):683-698.

9. Palermo TM, Drotar DD, Lambert S. Psychosocial predictors of children's postoperative pain. Clin Nurs Res. 1998;7(3):275-291.

10. Gidron Y, McGrath PJ, Goodday R. The physical and psychosocial predictors of adolescents' recovery from oral surgery. J Behav Med. 1995;18(4):385-399.

11. Bennett-Branson SM, Craig KD. Postoperative pain in children: Developmental and family influences on spontaneous coping strategies. Can J Behav Sci. 1993;25(3):355-383.

12. Crandall M, Lammers C, Senders C, Braun JV. Children's tonsillectomy experiences: influencing factors. $J$ Child Health Care. 2009;13(4):308-321.

13. Gillies ML, Smith LN, Parry-Jones WL. Postoperative pain assessment and management in adolescents. Pain. 1999;79(2/3):207-215.

14. Tripp DA, Stanish WD, Reardon G, Coady C, Sullivan MJ. Comparing postoperative pain experiences of the adolescent and adult athlete after anterior cruciate ligament surgery. J Athl Train. 2003;38(2): 154-157.

15. Perquin CW, Hazebroek-Kampschreur A, Hunfeld J, et al. Pain in children and adolescents: a common experience. Pain. 2000;87(1):51-58.

16. Hechler T, Blankenburg M, Dobe M, Kosfelder J, Hubner B, Zernikow B. Effectiveness of a multimodal inpatient treatment for pediatric chronic pain: a comparison between children and adolescents. Eur J Pain. 2010;14(1):97. e1-e9.

17. Hunfeld JAM, Perquin CW, Duivenvoorden HJ, et al. Chronic pain and its impact on quality of life in adolescents and their families. J Pediatr Psychol. 2001;26(3):145-153.

18. Martin AL, McGrath PA, Brown SC, Katz J. Children with chronic pain: impact of sex and age on long-term outcomes. Pain. 2007;128(1/2):13-19.

19. Fuss S, Pagé MG, Katz J. Persistent pain in a community-based sample of children and adolescents: gender differences in psychological constructs. Pain Res Manag. 2011;16(5):303-310.

20. Kotzer AM. Factors predicting postoperative pain in children and adolescents following spine fusion. Issues Compr Pediatr Nurs. 2000; 23(2):83-102.

21. de Moura LA, de Oliveira AC, Pereira Gde A, Pereira LV. Postoperative pain in children: a gender approach. Rev Esc Enferm USP. 2011;45(4):833-838. Portuguese.

22. Lamontagne LL, Hepworth JT, Salisbury MH. Anxiety and postoperative pain in children who undergo major orthopedic surgery. Appl Nurs Res. 2001;14(3):119-124.

23. Kain ZN, Mayes LC, Caldwell-Andrews AA, Karas DE, McClain B. Preoperative anxiety, postoperative pain, and behavioral recovery in young children undergoing surgery. Pediatrics. 2006;118(2):651-658.

24. Zvolensky MJ, Goodie JL, McNeil DW, Sperry JA, Sorrell JT. Anxiety sensitivity in the prediction of pain-related fear and anxiety in a heterogeneous chronic pain population. Behav Res Ther. 2001;39(6):683-696.

25. Crombez G, Eccleston C, Baeyens F, Eelen P. When somatic information threatens, catastrophic thinking enhances attentional interference. Pain. 1998;75(2/3):187-198.

26. Sullivan MJL, Bishop SR, Pivik J. The pain catastrophizing scale: development and validation. Psychol Assess. 1995;7:524-532.

27. Martin AL, McGrath PA, Brown SC, Katz J. Anxiety sensitivity, fear of pain and pain-related disability in children and adolescents with chronic pain. Pain Res Manage. 2007;12(4):267-272. 
28. Vervoort T, Goubert L, Eccleston C, Bijttebier P, Crombez G. Catastrophic thinking about pain is independently associated with pain severity, disability, and somatic complaints in school children and children with chronic pain. J Pediatr Psychol. 2006;31(7):674-683.

29. McCracken LM, Zayfert C, Gross RT. The Pain Anxiety Symptoms Scale: development and validation of a scale to measure fear of pain. Pain. 1992;50(1):67-73.

30. Pagé MG, Fuss S, Martin AL, Escobar EM, Katz J. Development and preliminary validation of the Child Pain Anxiety Symptoms Scale in a community sample. J Pediatr Psychol. 2010;35(10):1071-1082.

31. McCracken LM, Dhingra L. A short version of the Pain Anxiety Symptoms Scale (PASS-20): preliminary development and validity. Pain Res Manag. 2002;7(1):45-50.

32. Pagé MG, Campbell F, Isaac L, Stinson J, Martin-Pichora AL, Katz J. Reliability and validity of the Child Pain Anxiety Symptoms Scale (CPASS) in a clinical sample of children and adolescents with acute postsurgical pain. Pain. 2011;152(9):1958-1965.

33. March JS, Parker JDA, Sullivan K, Stallings P, Conners CK. The Multidimensional Anxiety Scale for Children (MASC): factor structure, reliability and validity. J Am Acad Child Adolesc Psychiatry. 1997;36(4):554-565.

34. Silverman WK, Fleisig W, Rabian B, Peterson RA. Childhood Anxiety Sensitivity Scale. J Clin Child Psychol. 1991;20(2):162-168.

35. Reiss S, McNally RJ. Expectancy model of fear. In: Reiss S, Bootzin RR, editors. Theoretical Issues in Behavior Therapy. San Diego, CA: Academic Press; 1985.

36. Crombez G, Bijttebier P, Eccleston C, et al. The child version of the Pain Catastrophization Scale (PCS-C): a preliminary validation. Pain. 2003;104:639-646.

37. Faulstich ME, Carey MP, Ruggiero L, Enyart P, Gresham F. Assessment of depression in childhood and adolescence: an evaluation of the Center for Epidemiological Studies Depression Scale for Children (CES-DC). Am J Psychiatry. 1986;143(8):1024-1027.

38. Fendrich M, Weissman MM, Warner V. Screening for depression disorder in children and adolescents: validating the center for epidemiologic studies depression scale for children. Am J Epidemiol. 1990;131(3):538-551

39. Walker LS, Greene JW. The functional disability inventory: measuring a neglected dimension of child health status. J Pediatr Psychol. 1991;16(1):39-58.

40. Kashikar-Zuck S, Vaught MH, Goldschneider KR, Graham TB, Miller JC. Depression, coping, and functional disability in juvenile fibromyalgia syndrome. J Pain. 2002;3(5):412-419.
41. Lynch AM, Kashikar-Zuck S, Goldschneider KR, Jones BA. Psychosocial risks for disability in children with chronic back pain. J Pain. 2006;7(4):244-251.

42. Reid GJ, McGrath PJ, Lang BA. Parent-child interactions among children with juvenile fibromyalgia, arthritis and healthy controls. Pain. 2005;113(1/2):201-210.

43. Von Baeyer CL. Numerical rating scale for self-report of pain intensity in children and adolescents: recent progress and further questions. Eur J Pain. 2009;13(10):1005-1007.

44. von Baeyer CL, Spagrud LJ, McCormick JC, Choo E, Neville K, Connelly MA. Three new datasets supporting use of the Numerical Rating Scale (NRS-11) for children's self-reports of pain intensity. Pain. 2009;143(3):223-227.

45. Canadian Pharmacists Association. Compendium of Pharmaceuticals and Specialties: The Canadian Reference for Health Professionals. Toronto, ON: Canadian Pharmacists Association; 2012.

46. Faul F, Erdfelder E, Buchner A, Lang A-G. Statistical power analyses using $\mathrm{G}^{*}$ Power 3.1: tests for correlation and regression analyses. Behav Res Methods. 2009;41(4):1149-1160.

47. Katz J, Seltzer Z. Transition from acute to chronic postsurgical pain: risk factors and protective factors. Expert Rev Neurother. 2009;9(5): 723-744.

48. Chambers CT, Craig KD, Bennett SM. The impact of maternal behavior on children's pain experiences: an experimental analysis. J Pediatr Psychol. 2002;27(3):293-301.

49. Piira T, Taplin JE, Goodenough B, von Baeyer CL. Cognitivebehavioural predictors of children's tolerance of laboratory-induced pain: implications for clinical assessment and future directions. Behav Res Ther. 2002;40(5):571-584.

50. Tsao JC, Glover DA, Bursch B, Ifekwunigwe M, Zeltzer LK. Laboratory pain reactivity and gender: relationship to school nurse visits and school absences. J Dev Behav Pediatr. 2002;23(4):217-224.

51. Claar RL, Walker LS. Functional assessment of pediatric pain patients: psychometric properties of the functional disability inventory. Pain. 2006;121(1-2):77-84.

52. Miaskowski C, Gear RW, Levine JD. Sex related differences in analgesic responses. In: Fillingrim RB, editor. Progress in Pain Research and Manageement. Vol 17. Seattle, WA: International Association for the Study of Pain Press; 2000.

53. Nikanne E, Kokki H, Tuovinen K. Postoperative pain after adenoidectomy in children. Br J Anaesth. 1999;82(6):886-889.

54. Voscopoulos C, Lema M. When does acute pain become chronic? $\mathrm{Br}$ J Anaesth. 2010;105(S1):i69-i85.
Journal of Pain Research

\section{Publish your work in this journal}

The Journal of Pain Research is an international, peer-reviewed, open access, online journal that welcomes laboratory and clinical findings in the fields of pain research and the prevention and management of pain. Original research, reviews, symposium reports, hypothesis formation and commentaries are all considered for publication.

\section{Dovepress}

The manuscript management system is completely online and includes a very quick and fair peer-review system, which is all easy to use. Visit http://www.dovepress.com/testimonials.php to read real quotes from published authors. 